LA-UR-9730 14
CONF- $970707--$

Los Alamos National Laboratory is operated by the University of California for the United States Department of Energy under contract W-7405-ENG-36

TITLE: MAGNETIC GUAGE INSTRUMENTATION ON THE LANL GAS-DRIVEN TWO-STAGE GUN

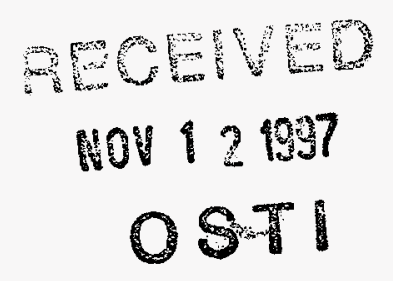

AUTHOR: Robert R. Alcon, Stephen A. Sheffield, A. Richard Martinez, and Richard L. Gustavsen, LANL, Los Alamos, NM 87545

SUBMITTED TO: 1997 Topical Conference on Shock Compression of Condensed Matter Amherst, Massachusetts, July 27 - August 1, 1997 


\section{DISCLAIMER}

Portions of this doenment may be illegible in electronic image products. Images are produced from the best available original docoment. 


\section{DISCLAIMER}

This report was prepared as an account of work sponsored by an agency of the United States Government. Neither the United States Government nor any agency thereof, nor any of their employees, make any warranty, express or implied, or assumes any legal liability or responsibility for the accuracy, completeness, or usefulness of any information, apparatus, product, or process disclosed, or represents that its use would not infringe privately owned rights. Reference herein to any specific commercial product, process, or service by trade name, trademark, manufacturer, or otherwise does not necessarily constitute or imply its endorsement, recommendation, or favoring by the United States Government or any agency thereof. The views and opinions of authors expressed herein do not necessarily state or reflect those of the United States Government or any agency thereof. 


\title{
MAGNETIC GAUGE INSTRUMENTATION ON THE LANL GAS-DRIVEN TWO-STAGE GUN ${ }^{\dagger}$
}

\author{
R. R. Alcon, S. A. Sheffield, A. R. Martinez, and R. L. Gustavsen
}

Los Alamos National Laboratory, Los Alamos, NM 87545

The LANL gas-driven two-stage gun was designed and built to do initiation studies on insensitive high explosives as well as equation of state and reaction experiments on other materials. The preferred method of measuring reaction phenomena involves the use of in-situ magnetic particle velocity gauges. In order to accommodate this type of gauging in our two-stage gun, it has a 50$\mathrm{mm}$-diameter launch tube. We have used magnetic gauging on our 72-mm bore diameter singlestage gun for over 15 years and it has proven a very effective technique for all types of shock wave experiments, including those on high explosives. This technique has now been installed on our gasdriven two-stage gun. We describe the method used, as well as some of the difficulties that arose during the installation. Several magnetic gauge experiments have been completed on plastic materials. Waveforms obtained in some of the experiments will be discussed. Up to 10 in-situ particle velocity measurements can be made in a single experiment. This new technique is now working quite well, as is evidenced by the data. To our knowledge, this is the first time magnetic gauging has been used on a two-stage gun.

\section{INTRODUCTION}

The two-stage gun is a compressed-helium driven, two-stage light gas gun (based on a design from Ernst Mach Institute[1]) designed to perform shock initiation studies on insensitive high explosives (see Fig. 1). It has a 100-mm diameter by $7.6-\mathrm{m}$ long pump tube and a $50-\mathrm{mm}$ diameter by 7.6-m long launch tube. The relatively large launch tube diameter of $50 \mathrm{~mm}$ was chosen to provide an experimental area large enough to allow onedimensional multiple magnetic gauge experiments to be done. A gas breech, capable of operating at $15,000 \mathrm{psi}$, is the driver for the pump piston. Three large hydraulic clamps are used to clamp the breech to the pump tube, the pump tube to the transition section, and the transition section to the launch tube. Helium is used as the driver gas for both the launch projectile and the pump piston. The 1-m diameter target chamber provides room for the electro-magnet which produces the magnetic field.

\footnotetext{
$\dagger^{\dagger}$ This work supported by the United States Department of Energy.
}

Projectile velocities in excess of $3 \mathrm{~km} / \mathrm{s}$ have been achieved with the breech charged to only $8000 \mathrm{psi}$. The gun design and performance have been described previously $(2,3,4)$

We have used magnetic particle velocity gauging for 15 years to measure the details of initiation in solid and liquid explosives initiated by projectile impact in a single-stage gun. This technique allows us to make up to 10 in-situ particle velocity measurements in a single experiment so that the shape of the reactive initiation shock can be monitored as it grows from the input shock to a detonation. With this type of experimental information available, functions can be developed to describe the global reaction process occurring. In this paper we briefly describe the gauge technique and how it is has been implemented on the two-stage gun. We believe this is a new technique as far as two-stage guns are concerned, and a number of changes to the gun design have been required to implement it. 


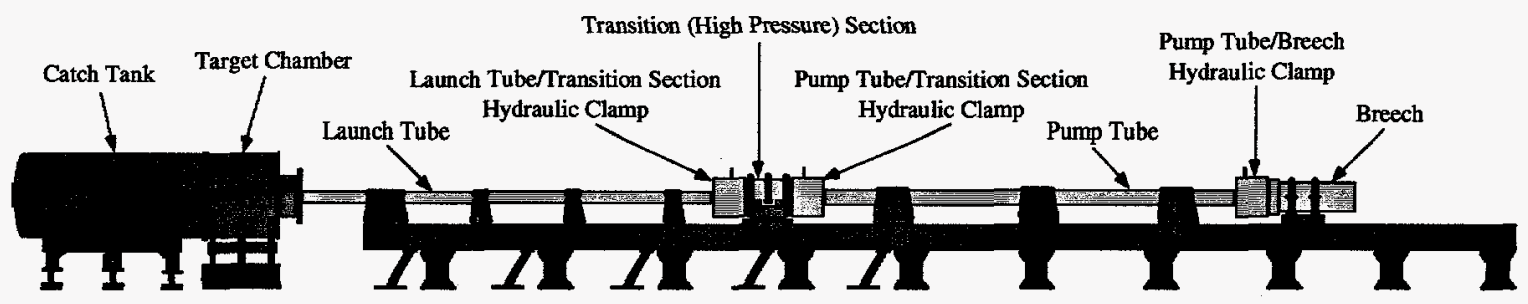

FIGURE 1. Schematic of the LANL gas-driven two-stage gun.

\section{MAGNETIC GAUGING TECHNIQUE}

Magnetic gauging was first used in Russia in 1957 (5) and later tried out by several groups. It has been used at a number of shock laboratories outside Russia over the years, but has achieved a prominent position in shock measurements over the years only in Russia and at Washington State University (WSU), SRI International, and Los Alamos National Laboratory. People at Physics International and WSU, $(6,7)$ along with several students who learned this technique, have been responsible for its implementation in the U.S.

Principle of Operation - The gauge function is quite simple. When a conductor in a closed loop moves in a magnetic field, a voltage is induced in the circuit because part of the loop cuts magnetic field lines as it moves. Output voltage depends on the magnetic field strength $(B)$, the length of the conductor $(l)$ cutting the field lines, and the velocity it is moving (v). This can be written as $E=B l v$ where $E$ is the voltage. $B$ and $l$ are measured before the experiment and $E$ is measured as a function of time during the experiment. From this the mass or particle velocity (at the particular Lagrangian position of the gauge) as a function of time can be obtained if the assumption is made that it moves with the material. In solid samples this is the case; liquids are more complicated (8).

Gauge Design - The LANL magnetic gauge technique development work was started by Vorthman and Wackerle in about 1980 (9). This technique involves the use of a thin gauge membrane $(60-\mu \mathrm{m}$ thick) that is embedded in the sample material so that in-situ particle velocity measurements are made. The gauge package is a sandwich of $25-\mu \mathrm{m}$-thick FEP Teflon, a 5- $\mu \mathrm{m}$-thick piece of aluminum foil (etched to the gauge configuration after gluing) glued to the Teflon, and another piece $25-\mu \mathrm{m}$-thick FEP Teflon glued on top as insulation. One gauge pattern is shown in Fig. 2.

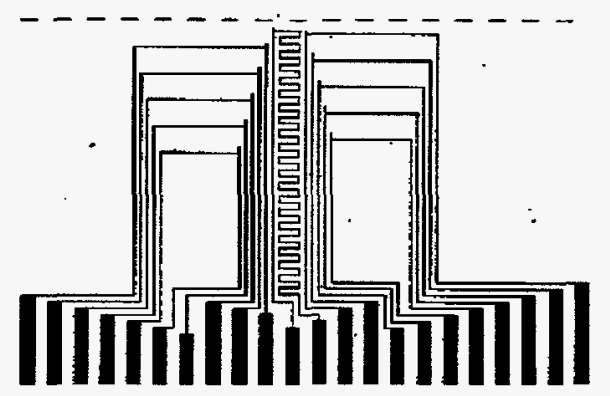

FIGURE 2. Details of the gauge pattern for a 10 gauge membrane with a shock tracker to track the shock velocity. Gauges are staggered so that 10 different positions can be measured in one experiment.

Target Design - In solid targets the sample is machined with a bottom and top designed so the gauge membrane can be glued in at an angle as shown in Fig. 3. Generally the angle is 30 degrees so that the gauge elements are $\approx 1 / 2 \mathrm{~mm}$ apart on the sample axis. The active gauge elements do not shadow each other. Typically the two-stage gun samples are $43-\mathrm{mm}$ diameter by about $23-\mathrm{mm}$ thick.

The target assembly is secured to a target plate with the position of the gauge ends carefully noted. The target plate is placed in the target chamber so that it is between the pole pieces of the electromagnet and the gauge ends are perpendicular to the magnetic field lines (and the gauge leads are parallel to the lines).

Magnet -- The magnetic field is developed by a large electromagnet located in the gun target chamber that is turned on just before the experiment. The two-stage gun magnet is capable 


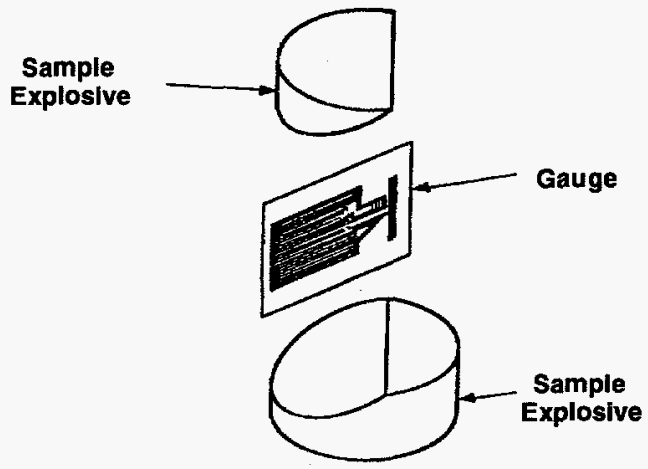

Experiment Pieces

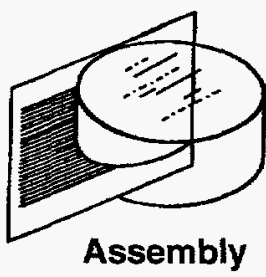

FIGURE 3. Schematic of the sample with the gauge membrane. Angle is usually 30 degrees. The assembly top is lightly machined after the gluing operation to make sure the top is flat.

of producing a field up to 2000 gauss but is normally operated at about 1000 gauss. The field is mapped before each experiment, just prior to installing the target assembly. A picture of the target chamber with the magnet installed is shown in Fig. 4. A 10-inch diam aluminum tube with a 1/2inch thick wall, centered between the magnet pole pieces and around the target, is used to protect the magnet and direct shot debris into the catch tank.

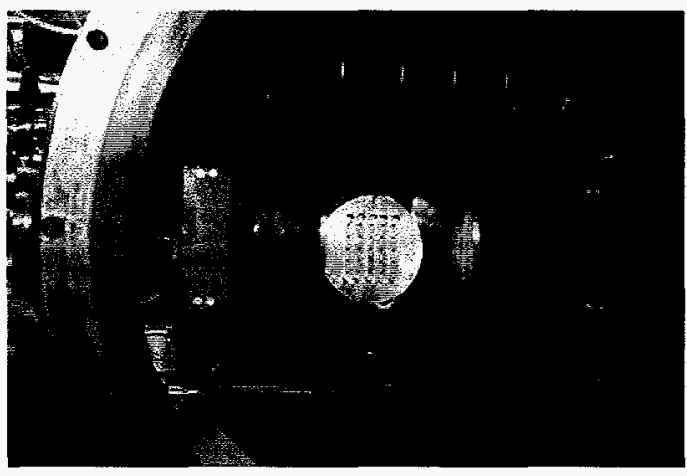

FIGURE 4. Picture of the target chamber with the electromagnet system installed. In the center is the plate with 25 holes used for mapping the magnetic field. The center hole of the plate is on the axis of the gun barrel. The target chamber is about 1-m diameter.
Two-Stage Gun Implementation - Initially the magnetic field in the two-stage gun was not as uniform as desired. This was due to two things: 1) the launch tube is 4340 steel, a magnetizable material, so it perturbs the field lines, and 2) it was necessary to put the target close to the end of the launch tube because the projectiles are short ( 2 to 3 inches long) and we want the projectile to impact the target before it is completely out of the launch tube to minimize tilt at impact. A mapping of the field in the region of the gauge allowed us to determine the field was uniform to about 2 percent. In addition, the most uniform region was about 2 inches past the center of the magnet due to lalunch tube distortion of the field. To help correct this problem, a 4-inch long stainless steel launch tube extension was installed and the launch tube was repositioned to accommodate it.

After this change was made, a new mapping of the magnetic field yielded the contour lines shown in Fig. 5. This figure shows that the uniformity of the field in the region of the gauge to be better than one percent. This is as good as the single-stage gun magnet which was what we were hoping for. The contour lines indicate the magnet is still positioned about 0.2 inch high but this is not considered a large amount considering the size of the magnet.

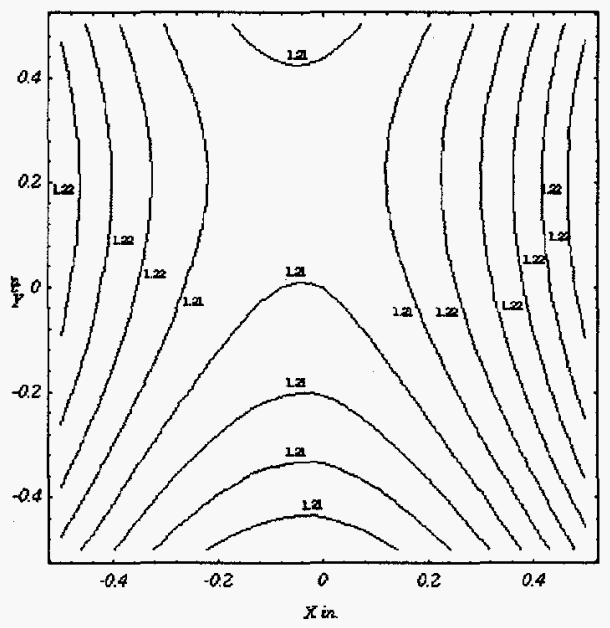

FIGURE 5. Contour plots of field calibration data from the twostage gun after modifications to the launch tube. Measurements were taken on the centerline of the magnet. The field varies from 1210 to 1220 gauss, indicating that the errors due to the magnetic field measurement are less than 1 percent. 


\section{MAGNETIC GAUGE EXPERIMENTS ON THE TWO-STAGE GUN}

Several multiple magnetic gauge experiments have been conducted on the two-stage gun with varying degrees of success, principally because we were working the bugs out of the system. These experiments involved either with polychlorotrifluoroethylene (Kel-F) or polymethylmethacrylate (PMMA) targets that were impacted by polycarbonate (Lexan) projectiles. The targets were as shown in Fig. 3 with 10 gauge elements as shown in Fig. 2. The finished target was a cylinder $43 \mathrm{~mm}$ diam by $23 \mathrm{~mm}$ high.

Shot 2 s-11 was a PMMA target impacted by a Lexan projectile at a velocity of $2.8 \mathrm{~km} / \mathrm{s}$. A gauge package with ten gauges was used but only nine gauge voltages were successfully recorded. The particle velocity data from the shot are shown in Fig. 6. The particle velocity measured was about $1.35 \mathrm{~mm} / \mu \mathrm{s}$. Data from the shock tracker gave a shock velocity of $4.76 \mathrm{~mm} / \mu \mathrm{s}$. This translates into a pressure in the PMMA of $7.6 \mathrm{GPa}$. This data point agrees reasonably well with other PMMA data (10). We take this to mean that the magnetic gauging technique is working properly on the two-stage gun and will provide good data. . The waveforms have some rounding at the top which is evidence that there is still viscoelastic behavior even at $7.6 \mathrm{GPa}$ in PMMA.

In Fig. 6, five particle velocity waveforms came from one side of the experiment and 4 came from the other side. These are not evenly spaced because there were problems with projectile tilt at impact on this experiment. If the tilt had been very small (less than 0.1 mradian) the waveforms would have been equally spaced in time. The offset from this equal spacing indicates that there was a few mradians of tilt in the experiment. There are several aspects of the gun setup that have a bearing on this: 1) the straightness of the launch tube, 2) the mating of the heavy catch tank to the target chamber, and 3) the alignment of the target with respect to the launch tube muzzle. These are being looked into at the present time to find the problem and eliminated it. Tilt of less than a mradian is desired.

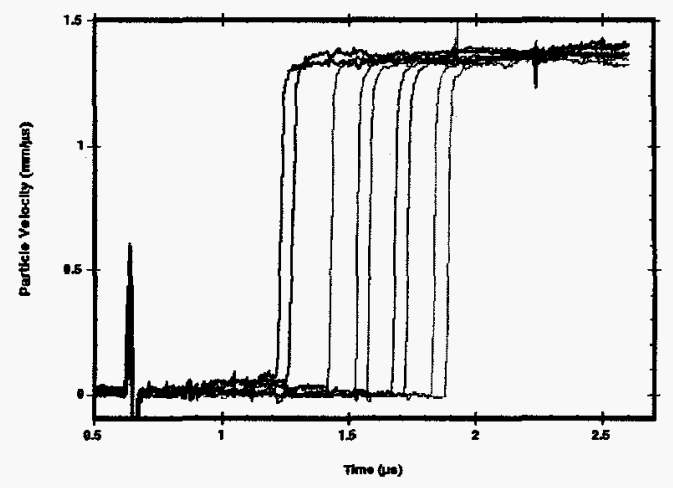

FIGURE 6. Particle velocity waveforms from Shot $2 s-11$. There are only 9 gauge measurements because 1 gauge was not recorded properly.

\section{REFERENCES}

1. Stilp, A. J., "The New EMI Terminal Ballistics and Hypervelocity Impact Range," unpublished report, Ernst Mach Institut, Freiburg, Germany, August 1987.

2. Martinez, A. R., Sheffield, S. A., Whitehead, M. C., Olivas, H. D., and Dick, J. J., "New LANL Gas Driven Two-Stage Gun," in High-Pressure Science and Technology -- 1993, Eds. S. C. Schmidt, J. W. Shaner, G. A. Samara, and M. Ross, American Institute of Physics (AIP) Conference Proceedings No. 309 (1994) p. 1643

3. Sheffield, S. A., and Martinez, A. R., "New LANL Group M-7 Two-Stage Gun: Double Diaphragm and Wrap-Around Gas Breech," presented at the 43rd Aeroballistic Range Association (ARA) Meeting, Columbus, Ohio, Sept. 28 - Oct. 2, 1992.

4. Sheffield, S. A., and Martinez, A. R., "Testing of New LANL Gas-Driven Two-Stage Gun," presented at the 45th Aeroballistic Range Association (ARA) Meeting, Huntsville, Alabama, Oct. 10-14, 1994.

5. Pohkil \& Dremin

6. Koller, L. R., "Generation and Measurement of Simultaneous Compression-Shear Waves in Arkansas Novaculite," Ph.D. Thesis at Washington State University under RFowles, 1978.

7. Young, C., Fowles, R., and Swift, R. P., inShock Waves and the Mechanical Properties of Solids, Eds. J. J. Burke and V. Weiss, Syracuse University Press, 1971, p. 203.

8. Gustavsen, R. L., and Sheffield, S. A., "Response of Inclined Electromagnetic Particle Velocity Gauges in Shocked Liquids," in High Pressure Science and Technology .- 1993, Eds. S. C. Schmidt, J. W. Shaner, G. A. Samara, and M. Ross, American Institute of Physics (AIP) Conference Proceedings 309 (1994), p. 1703.

9. Vorthman, J. E., "Facilities for the Study of Shock In-duced Decomposition of High Explosives," in Shock Waves in Condensed Matter -- 1981, Eds. W. J. Nellis, L. Seaman, and R. A. Graham, American Institute of Physics (AIP) Conference Proceedings No. 78 (1982) p. 680.

10. Carter, W. J., and Marsh, S. P., "Hugoniot Equation of State of Polymers," Los Alamos National Laboratory Report, LA-13006MS, July 1995. 